\title{
A New Way to Determine Engineering Cost Price in the Construction Engineering Tendering
}

\author{
Shumei Cui \\ Civil Engineering Institution, Yantai University, china \\ cuishumei623@163.com
}

\begin{abstract}
Keywords: Construction Engineering Tendering; the Lowest Bid Method; Bid Evaluation Cost Price; Multiple Attribute Decision Making Theory; Overall values
\end{abstract}

\begin{abstract}
The lowest bid method should be used in the bid evaluation of construction engineering, and it is a critical problem that how to calculate the lowest cost price of the bid proposal. In this paper, a new model is proposed, based on multiple attribute decision making theory. According to the tenderer's preference that indicates their feelings towards difference in strength of technology and management between the bidders, the deviation minimization and maximization decision method are adopted. We establish the optimized decision model. This model has been successfully applied in the formulation of bid proposal of construction engineering in Yantai.
\end{abstract}

\section{Introduction}

It is formulated by the Bidding Law of the People's Republic of China that the comprehensive evaluation method and the lowest bid method. The latter should be used in the bid evaluation of construction engineering which adopted bill of quantities. But the lowest bid price by assessment should not be lower than the cost of the enterprise. Generally speaking, there are some ways to estimate the bid evaluation cost price. The first one, the tenderer calculates the cost price based on the social average level. The second one, calculate the weighted average of the price estimated by the construction department and the mean of all the bidders' prices as the bid evaluation base price. The third one is to calculate the mean of all the bidders' prices as the bid evaluation base price. Then, it may be fallen to a certain extent as the bid evaluation cost price. The bid, which price is lower than that, is invalid. These methods are based on the hypothesis that all the bidders are at the same social average level. When a bidder puts forward a low bid price, because it has advanced technology and management, it may be excluded. It is easy to make the owner lose the most competitive quotation and unfair to the higher-level bidder ${ }^{[1]}$.

Therefore, based on the bidders' level of technology and management, the paper proposed a new way to determine the evaluation bid cost price. This method can make the tenderer treat the bidders differently according to their level of technology and management.

\section{Multi-attribute theory of decision-making model [2]}

When the tenderer account that there is too much strength gap on technology and management between the bidders, the method of deviation maximization would be adopted to make the gap the biggest, which is between overall attribute values of all the bidding projects.

$$
\text { If } y_{i j}=f_{j}\left(x_{i}\right)(i=1,2, \cdots, m ; j=1,2, \cdots, n) \text { are the values of the bidders }{ }^{x_{i}} \text { under the attribute } f_{j} \text {. }
$$

The decision matrix of attribute set $F$ with the regard to the bidders set $X$ is expressed by the matrix Y.

$$
Y=\left[\begin{array}{cccc}
y_{11} & y_{12} & \cdots & y_{1 n} \\
y_{21} & y_{22} & \cdots & y_{2 n} \\
\vdots & \vdots & \ddots & \vdots \\
y_{m 1} & y_{m 2} & \cdots & y_{m n}
\end{array}\right]
$$


We suppose that $Y$ has been handled.

When $\mathrm{W}$ is partly or completely unknown and the strength gap between the bidders is large, expressed as the formula (2).

$$
\left\{\begin{array} { l } 
{ \operatorname { m a x } Z ( W ) = \sum _ { i = 1 } ^ { m } \sum _ { j = 1 } ^ { n } \sum _ { k = 1 } ^ { m } | y _ { i j } - y _ { k j } | w _ { j } } \\
{ \text { s.t. } \sum _ { j = 1 } ^ { n } w _ { j } = 1 , w _ { j } \geq 0 , j \in N . }
\end{array} \quad \left\{\begin{array}{l}
\min Z(W)=\sum_{i=1}^{m} \sum_{j=1}^{n} \sum_{k=1}^{m}\left|y_{i j}-y_{k j}\right| w_{j} \\
\text { s.t. } \sum_{j=1}^{n} w_{j}=1, w_{j} \geq 0, j \in N .
\end{array}\right.\right.
$$

When the tenderer account that the comprehensive strength gap of the bidders is small, the deviation minimization decision method ${ }^{[3]}$ would contribute to identify cost price and make the gap of all the projects' overall attribute value the least, expressed as the formula (3).

This model can be obtained by the analytical method in mathematics, and it is mature in theory, which is located in Ref. [4] [5].

\section{A new way to determine the bid evaluation cost price}

The new way depends on the bidding information of the same bidder and the tenderer's preference which indicates their feelings towards difference in strength of technology and management between the bidders.

According to the tenderer's subjective preference, a decision problem is put up with the evaluation information of the proposals' deviation. The decision matrix $Y=\left(y_{i j}\right)_{m n}$ is a real number one. Just as expressed in (1), the weights of all the bid evaluation factors are partly or completely unknown, the deference degree of the bidding scheme which is perceived by the tenderer is the real number $\lambda \in[0$, 1]. A new decision model is given by the following steps.

The first step, according to (2) and (3), the largest and smallest deviations are given.

$\operatorname{MaxZ}(\mathrm{W})=\mathrm{a}, \operatorname{MinZ}(\mathrm{W})=\mathrm{b}$.

The second step, adopt $Z^{*}=b+\lambda(a-b)$ and establish the following optimized decision model, to make the objective decision information of the matrix $Y=\left(y_{i j}\right) m n$ agree with the subjective assessment of the tenderer.

$$
\left\{\begin{array}{l}
\min \left|Z(W)-Z^{*}\right|=\left|\sum_{i=1}^{m} \sum_{j=1}^{n} \sum_{k=1}^{m}\right| y_{i j}-y_{k j}\left|w_{j}-Z^{*}\right| \\
\text { s.t. } \sum_{j=1}^{n} w_{j}=1, w_{j} \geq 0, j \in N
\end{array}\right.
$$

The third step is to solve the model (4) and get the weights vector W.

The fourth step, according to the result, the overall attribute value can be got by the method of weight sum, and then it is easy to get the order of all the bidding schemes. The rate of the fallen cost is equal to the competitive cost ratio by the overall attribute value. So the bidding scheme is the optimal one which holds the highest overall attribute value. And it can make the cost be lowest.

\section{Engineering example}

There are 8 bidders for it and their bid price is in Table 1. Because this project is a general one, the rate of the competitive price s $15 \%$.i

Table 1 the bid price of all bidders

\begin{tabular}{|c|c|c|c|c|c|c|c|c|}
\hline $\begin{array}{c}\text { Name } \\
\text { of the } \\
\text { bidders }\end{array}$ & A & B & C & D & E & F & G & H \\
\hline $\begin{array}{c}\text { bid } \\
\text { price }\end{array}$ & 3308.2 & 3939.2 & 3704.3 & 3746.4 & 3033.4 & 4389.3 & 3206.4 & 3704.1 \\
\hline Average & \multicolumn{8}{|c|}{3601.41 (removing the highest and the lowest ones) } \\
\hline
\end{tabular}


\begin{tabular}{|l|l} 
bid price & The competitive cost is 540.2 ten thousand yuan
\end{tabular}

The base price to determine the bid cost price is 3601.4 ten thousand yuan.

The five factors are graded as excellent $(\mathrm{E})$, good $(\mathrm{G})$, fair $(\mathrm{F})$ and poor $(\mathrm{P})$ and the scores are respectively $90,80,70,60$. The bid evaluation experts evaluate all the factors of the bidders as in table 2. If the tenderer supposes that the schemes' deference is not large and $\lambda=0.2$.

Table 2 the grades of all the factors of every bidder

\begin{tabular}{|c|r|r|r|r|r|r|r|r|}
\hline Evaluation Item & A & B & C & D & E & F & G & H \\
\hline $\begin{array}{c}\text { Construction organization } \\
\text { design }\end{array}$ & E & F & G & F & E & P & E & F \\
\hline Financial capability & G & G & G & G & E & F & E & G \\
\hline Technical capability & E & G & G & F & E & P & E & F \\
\hline Achievements & E & G & G & G & E & F & G & G \\
\hline Reputation & G & E & F & G & E & G & E & G \\
\hline
\end{tabular}

The corresponding scores are in table 3.

Table 3 the corresponding scores of all the bidders

\begin{tabular}{|c|r|r|r|r|r|r|r|r|}
\hline Evaluation Item & A & B & C & D & E & F & G & H \\
\hline $\begin{array}{c}\text { Construction } \\
\text { organization design }\end{array}$ & 90 & 70 & 80 & 70 & 90 & 60 & 90 & 70 \\
\hline Financial capability & 80 & 80 & 80 & 80 & 90 & 70 & 90 & 80 \\
\hline Technical capability & 90 & 80 & 80 & 70 & 90 & 60 & 90 & 70 \\
\hline Achievements & 90 & 80 & 80 & 80 & 90 & 70 & 80 & 80 \\
\hline Reputation & 80 & 80 & 70 & 80 & 90 & 80 & 90 & 80 \\
\hline
\end{tabular}

The multiple attribute decision making theory is used to define the affect of all the bid schemes. The weights' values are partly unknown.

At first, exploiting linear converter technique, getting the decision matrix as in table 4,

Table 4 Decision matrix

\begin{tabular}{|c|c|c|c|r|r|r|r|r|}
\hline Evaluation Item & $\mathrm{A}$ & $\mathrm{B}$ & $\mathrm{C}$ & $\mathrm{D}$ & $\mathrm{E}$ & $\mathrm{F}$ & $\mathrm{G}$ & $\mathrm{H}$ \\
\hline $\begin{array}{c}\text { Construction } \\
\text { organization design }\end{array}$ & 1 & 0.78 & 0.89 & 0.78 & 1 & 0.67 & 1 & 0.78 \\
\hline Financial capability & 0.89 & 0.89 & 0.89 & 0.89 & 1 & 0.78 & 1 & 0.89 \\
\hline $\begin{array}{c}\text { Technical } \\
\text { capability }\end{array}$ & 1 & 0.89 & 0.89 & 0.78 & 1 & 0.67 & 1 & 0.78 \\
\hline Achievements & 1 & 0.89 & 0.89 & 0.89 & 1 & 0.78 & 0.89 & 0.89 \\
\hline Reputation & 0.89 & 0.89 & 0.78 & 0.89 & 1 & 0.89 & 1 & 0.89 \\
\hline
\end{tabular}

Get the model as the following according to the formula (2).

$\left\{\begin{array}{l}\max Z(W)=1.839 w_{1}+0.557 w_{2}++1.718 w_{3}+0.557 w_{4}+0.557 w_{5} \\ \text { s.t. } 0.3 \leq w_{1} \leq 0.5,0.1 \leq w_{2} \leq 0.3,0.2 \leq w_{3} \leq 0.4,0.1 \leq w_{4} \leq 0.2,0.1 \leq w_{5} \leq 0.2 \\ \sum_{j=1}^{5} w_{j}=1\end{array}\right.$

Get the result to solve the model (5). $\max Z(W)=1.43$

Get the model as the following according to the formula (3).

$\left\{\begin{array}{l}\min Z(W)=1.839 w_{1}+0.557 w_{2}++1.718 w_{3}+0.557 w_{4}+0.557 w_{5} \\ \text { s.t. } 0.3 \leq w_{1} \leq 0.5,0.1 \leq w_{2} \leq 0.3,0.2 \leq w_{3} \leq 0.4,0.1 \leq w_{4} \leq 0.2,0.1 \leq w_{5} \leq 0.2 \\ \sum_{j=1}^{5} w_{j}=1\end{array}\right.$

Get the result to solve the model (6). $\min Z(W)=1.174$ And 
$\mathrm{Z}^{*}=\mathrm{b}+\lambda(\mathrm{a}-\mathrm{b})=\min \sigma(W)+0.2(\max \sigma(W)-\min \sigma(W))=1.225$

Get the model as the following according to the formula (4).

$\left\{\begin{array}{l}\min \left|Z(W)-Z^{*}\right|=\left|1.839 w_{1}+0.557 w_{2}++1.718 w_{3}+0.557 w_{4}+0.557 w_{5}-Z^{*}\right| \\ \text { s.t. } 0.3 \leq w_{1} \leq 0.5,0.1 \leq w_{2} \leq 0.3,0.2 \leq w_{3} \leq 0.4,0.1 \leq w_{4} \leq 0.2,0.1 \leq w_{5} \leq 0.2 \\ \sum_{j=1}^{5} w_{j}=1\end{array}\right.$

Get the result to solve the model (7). ${ }^{\min \left|Z(W)-Z^{*}\right|}=0 ; \mathrm{W}=(0.34,0.1,0.2,0.18,0.18)$

The overall attribute value of all the schemes $x_{i}(i=1,2, \ldots, 8)$ is got by weighted sum and is respectively: $0.9692,0.8526,0.8702,0.8306,1,0.7404,0.9802$, and 0.8306 . Take the bidder A for example. The magnitude of the bid price be reduced is got by the formula: $15 \% \times 0.9692=0.1454$, when the overall attribute value of $\mathrm{A}$ is 0.9692. And the lowest acceptable cost is: $3601.411 \times(1-0.1455)=3077.838$ (ten thousand yuan). The situations of all the bidders are in table 5 .

Table 5 the bidders' situations

\begin{tabular}{|c|c|c|c|c|c|c|}
\hline $\begin{array}{l}\text { Name of the } \\
\text { bidders }\end{array}$ & Bid price & \begin{tabular}{|l} 
Overall \\
Attribute \\
Value \\
\end{tabular} & $\begin{array}{l}\text { Rate of the cost } \\
\text { that can fall }\end{array}$ & Cost Price & $\begin{array}{l}\text { Invalid bid } \\
\text { or not }\end{array}$ & Remark \\
\hline $\mathrm{A}$ & 3308.2 & 0.9692 & 0.1454 & 3077.8 & no & \multirow{8}{*}{$\begin{array}{l}\text { The bid } \\
\text { prices } \\
\text { of al } \\
\text { the } \\
\text { bidders } \\
\text { are } \\
\text { above } \\
\text { the cost } \\
\text { price, } \\
\text { so }\end{array}$} \\
\hline $\mathrm{B}$ & 3939.2 & 0.8526 & 0.1279 & 3140.8 & no & \\
\hline $\mathrm{C}$ & 3704.3 & 0.8702 & 0.1305 & 3131.3 & no & \\
\hline $\mathrm{D}$ & 3746.4 & 0.8306 & 0.1246 & 3152.7 & no & \\
\hline$E$ & 3033.4 & 1 & 0.1500 & 3061.2 & no & \\
\hline $\mathrm{F}$ & 4389.2 & 0.7404 & 0.1111 & 3201.4 & no & \\
\hline G & 3206.4 & 0.9802 & 0.1470 & 3071.9 & no & \\
\hline $\mathrm{H}$ & 3704.1 & 0.8306 & 0.1246 & 3152.7 & no & \\
\hline
\end{tabular}

According to Table 5, the bidder E can award of tender.

\section{Conclusion}

To the general construction project, a practical method to determine the cost price is put up in this paper. After considering the affect of other factors to the bid price, the tenderer can get the cost price of the bidders by the way. Through this way, the bidders of different levels of technology and management can be treated differently, which can ensure that the bidders' quotation is not lower than its own cost, and make the owner get the most competitive bid price. Whereas, there should be deflects in every method, so we hope that it can be improved gradually.

\section{References}

[1] Lejie Wu: An Assessment Study on the Lowest Cost of Tender Corporation Based on the Lowest Price Calling for Tenders model (Master's thesis, Xi'an University of Architecture Technology, 2006).

[2] Chank tong V and Haines Y: Multrobjective Decision Making Theory and Methodology, edited by Elsevier North Holland, New York, NY (1983), in press.

[3] Fangwei Zhang:Journal of shandong university(Natural Science), Vol. 42 (2007), p. 32.

[4] Yunquan Hu. Operational Research Tutorial (Third Edition), edited by Tsinghua University Press, Beijing, NY (2011).

[5] Chaoyuan Yue: Decision Theory and Methods, edited by Science Press, Beijing, NY (2006). 